\title{
Dinâmica de Nutrientes em Tecidos Foliares de Cana-de-Açúcar APÓS APLICAÇÃo de HERBICIDAS ${ }^{1}$
}

\author{
Nutrient Dynamics in Sugar Cane Foliar Tissues After Herbicide Application
}

\author{
REIS, M.R. ${ }^{2}$, SILVA, A.A. ${ }^{3}$, GUIMARÃES, A.A. ${ }^{4}$, KHOURI, C.R. ${ }^{5}$, FERREIRA, E.A. ${ }^{2}$, FERREIRA, F.A. ${ }^{6}$ \\ e FREITAS, M.A.M. ${ }^{4}$
}

\begin{abstract}
RESUMO - Avaliaram-se, neste trabalho, os efeitos dos herbicidas ametryn, 2,4-D, trifloxysulfuron-sodium e da mistura ametryn+trifloxysulfuron-sodium na nutrição mineral e no crescimento da cana-de-açúcar. Para isso, utilizou-se o delineamento inteiramente casualizado no esquema de parcelas subdivididas, com quatro repetições. Os efeitos dos herbicidas foram avaliados nas parcelas, e o efeito do tempo, expresso em dias após aplicação dos herbicidas (DAA), considerando as diversas amostragens nas subparcelas. Os herbicidas foram aplicados em pós-emergência, quando as plantas de cana-de-açúcar se apresentavam com três a quatro folhas. As características avaliadas foram: a altura e massa seca da parte aérea, o número de folhas, o número de perfilhos e as concentrações de macro e micronutrientes nos tecidos foliares das plantas. As concentrações de N, P e Mg nos tecidos foliares não foram afetadas pelo uso dos herbicidas, independentemente da época de avaliação (15, 30, 45 e 60 DAA). Ao longo do tempo após a aplicação, constatou-se acréscimo da taxa de acúmulo (coeficiente $\beta_{0}$ ) dos nutrientes catiônicos $\mathrm{Ca}$, $\mathrm{Mg}$ e $\mathrm{K}$ em plantas expostas ao ametryn+trifloxysulfuron-sodium. Quando da aplicação do 2,4-D, verificou-se redução na taxa de acúmulo de $\mathrm{S}$ e alteração na dinâmica dos nutrientes $\mathrm{Mg}, \mathrm{Ca}$ e $\mathrm{K}$, comparado à testemunha sem herbicida. Os herbicidas provocaram redução na concentração de Fe nessa cultura aos $15 \mathrm{DAA}$, na seguinte ordem: ametryn+trifloxysulfuron-sodium > ametryn > trifloxysulfuron-sodium > 2,4-D. Em relação às plantas de cana-de-açúcar não tratadas com herbicida (testemunha), o herbicida trifloxysulfuron-sodium provocou acréscimo de $22,10 \%$ no acúmulo de massa seca da sua parte aérea aos 60 DAA. O número de perfilhos observados em plantas tratadas com trifloxysulfuron-sodium foi o dobro do encontrado com ametryn, demonstrando efeito negativo deste herbicida nessa caracteristica. Evidenciaramse neste trabalho os efeitos dos herbicidas na concentração dos nutrientes e o crescimento das plantas de cana-de-açúcar.
\end{abstract}

Palavras-chave: 2,4-D, ametryn, trifloxysulfuron-sodium, macronutrientes, micronutrientes.

\begin{abstract}
The objective of this work was to evaluate the impact of the herbicides ametryn and trifloxysulfuron-sodium, alone or combined, and 2, 4-D, on mineral nutrition and growth in sugar cane plants. Sugar cane plants with three to four fully expanded leaves were sprayed with ametryn, trifloxysulfuron-sodium, and ametryn + trifloxysulfuron-sodium at the doses of 1.30; 1.00; 0.0225 , and $1.463+0.0375 \mathrm{Kg} \mathrm{ha}^{-1}$, respectively. A completely randomized design was adopted in a split-plot scheme with four replications. Herbicide effect was evaluated in the whole plots and the effect of time after application in the split-plots. At 15, 30, 45, and 60 days after spraying (DAA), leaf tissue samples were collected and analyzed for height and dry mass of the shoots, number of leaves and tillers, and foliar concentrations of macro and micronutrients of sugar cane plants. The leaf concentrations of $N, P$ and $M g$ were not affected by herbicide use. After herbicide spraying, increase in the accumulation rate (coefficient $\beta_{0}$ ) of the cationic nutrients
\end{abstract}

1 Recebido para publicação em 29.4.2007 e na forma revisada em 3.1.2008.

2 Engo-Agró-, Estudante de Doutorado do Dep. Fitotecnia, Universidade Federal de Viçosa - UFV, 36570-000, Viçosa-MG, <reisagro@yahoo.com.br>; ${ }^{3}$ D.Sc., Professor Associado do Depto. de Fitotecnia - UFV; ${ }^{4}$ Graduando(a) em Agronomia, Bolsista de Iniciação Científica - DFT/UFV; 5 Eng ${ }^{-}-$Agr $^{0}$, Mestre em Fitotecnia - UFV; ${ }^{6}$ D. Sc., Professor Titular do Dep. de Fitotecnia UFV.

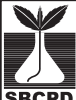

Planta Daninha, Viçosa-MG, v. 26, n. 1, p. 175-184, 2008 
$\mathrm{Ca}, \mathrm{Mg}$ and $\mathrm{K}$, was observed in the plants treated with ametryn + trifloxysulfuron-sodium. When 2, 4-D was applied, a reduction in the accumulation rate of the $S$ and alteration in the dynamics of the nutrients $\mathrm{Mg}, \mathrm{Ca}$ and $\mathrm{K}$ were verified in relation to the other treatments. The herbicides reduced the iron concentration in sugar cane plants to $15 \mathrm{DAA}$, in the following order: ametryn+trifloxysulfuron-sodium > ametryn > trifloxysulfuron-sodium > 2, 4-D. At 60 DAS, trifloxysulfuron-sodium led to increase of $22.10 \%$ in biomass accumulation of the sugar cane shoots in comparison to the control treatment without herbicide application. The number of tillers plants treated with trifloxysulfuron-sodium was double in relation that of those treated with ametryn, evidencing negative effect ametryn. This work evidences herbicide effects on the concentration of leaf nutrients and growth of sugar cane plants.

Keywords: 2,4-D, ametryn, trifloxysulfuron-sodium, macronutrients, micronutrients.

\section{INTRODUÇÃO}

O Brasil é o maior produtor mundial de cana-de-açúcar, gerando mais de 400 milhões de toneladas por ano, com cerca de seis milhões de hectares de área cultivada (Magalhães, 2005). Uma das variedades de cana-de-açúcar mais plantadas no Brasil é a RB867515, a qual apresenta boa produtividade e tolerância a importantes doenças da cultura (PMGCA, 2005).

A cultura da cana-de-açúcar, assim como outras, é suscetível à interferência das plantas daninhas. Para manejo dessas plantas, os herbicidas tornaram-se ferramentas indispensáveis. Isso se deve à alta eficiência e rapidez na operação de controle quando da utilização desses produtos, tornando possivel o cultivo de grandes áreas com pouca dependência de mãode-obra. Adicionalmente, o custo do controle químico de plantas daninhas na cana-de-açúcar é equivalente ou inferior ao dos outros métodos (Silva et al., 2007). Atualmente, no Brasil, encontram-se disponiveis 135 herbicidas (produtos comerciais) registrados para controle de plantas daninhas na cultura da cana-deaçúcar (ANVISA, 2006). Dentre esses, destacase o 2,4-D, o ametryn e o trifloxysulfuron-sodium. O 2,4-D pertence ao grupo químico dos fenoxiacéticos, utilizado no controle de dicotiledôneas, apresentando baixos níveis de intoxicação à cultura (Procópio et al., 2003). O ametryn, inibidor do fotossistema II, controla com eficiência diversas espécies daninhas mono e dicotiledôneas, podendo ser aplicado em pré ou em pós-emergência inicial das plantas daninhas, sendo bem tolerado pela cul- tura da cana-de-açúcar (Rodrigues \& Silva, 2005). O trifloxysulfuron-sodium, o qual pertence ao grupo químico das sulfoniluréias e inibe a ação da enzima acetolactato sintase (ALS) em plantas suscetiveis, controla com eficiência diversas dicotiledôneas e gramíneas, podendo ser usado em pós-emergência isolado ou em mistura com ametryn - mistura comercial denominada Krismat ${ }^{\circledR}$ (Hudetz, 2000; Procópio et al., 2003). Em conseqüência da boa tolerância da cultura a essa mistura e também pelo amplo espectro de ação (Freitas et al., 2004; Durigan, 2005; Durigan, 2006), o uso do Krismat $^{\circledR}$ tem-se expandido rapidamente nas áreas cultivadas com cana-de-açúcar por todo o Brasil. Todavia, apesar de a maioria das variedades de cana-de-açúcar, inclusive a variedade RB867515, apresentar boa tolerância ao Krismat, são comuns sintomas de intoxicação na cultura causados pelos herbicidas (Ferreira et al., 2005).

Considerando que a intoxicação de plantas por herbicidas pode afetar o potencial destas em absorver e utilizar os nutrientes disponíveis na solução do solo, acredita-se que a tolerância de uma cultura a herbicidas, pragas e doenças seja também influenciada pelo seu estado nutricional (Chaboussou, 1999). Essa teoria foi confirmada por Mishra \& Kurchania (2001) e Rana (2000), os quais verificaram alterações nas concentrações de macronutrientes em tecidos foliares de arroz e mostarda em conseqüência de aplicações dos herbicidas butachlor na cultura do arroz e isoproturon e oxadiazon em mostarda. Neste trabalho, objetivou-se avaliar o efeito dos herbicidas 2,4-D, ametryn, trifloxysulfuron-sodium e da mistura 
comercial ametryn+trifloxysulfuron-sodium na nutrição mineral e no crescimento de plantas de cana-de-açúcar da variedade RB 867515.

\section{MATERIAL E MÉTODOS}

O experimento foi conduzido em casa de vegetação pertencente ao Departamento de Fitotecnia da Universidade Federal de Viçosa - UFV, e no Laboratório de Nutrição Mineral/ UFV, Viçosa, MG.

Para cultivo da cana-de-açúcar utilizaram-se vasos de PVC de coloração preta, preenchidos com 10 L de substrato, com o interior revestido por filme de polietileno. O solo utilizado foi o Latossolo Vermelho-Amarelo, extraído do horizonte $\mathrm{B}$ do perfil do solo de área sem histórico de aplicação de agrotóxicos, previamente corrigido com calcário dolomítico $\left(0,15 \mathrm{~g} \mathrm{dm}^{-3}\right)$ e adubado com os fertilizantes: sulfato de amônio $\left(0,09 \mathrm{~g} \mathrm{dm}^{-3} \mathrm{de} \mathrm{N}\right)$, superfosfato simples $\left(1,8 \mathrm{~g} \mathrm{dm}^{-3}\right.$ de $\left.\mathrm{P}_{2} \mathrm{O}_{5}\right)$ e cloreto de potássio $\left(0,34 \mathrm{~g} \mathrm{dm}^{-3} \mathrm{de}_{2} \mathrm{O}\right)$. Posteriormente à correção e adubação, o solo foi analisado física e quimicamente (Tabela 1). O material propagativo de cana-de-açúcar constituiu-se de fragmentos de colmos (tolete contendo uma gema) da variedade RB867515, sendo plantados dois toletes por vaso. Foram também realizadas adubações de cobertura com $100 \mathrm{~mL}$ de solução assim preparada: adubo Ouro Verde ${ }^{\circledR}$, contendo (dag kg ${ }^{-1}$ : $\mathrm{N}(15,0), \mathrm{P}_{2} \mathrm{O}_{5}(15,0), \mathrm{K}_{2} \mathrm{O}(20,0), \mathrm{CaO}$ $(3,0), \mathrm{S}(4,0) ; \mathrm{MgO}(0,8), \mathrm{Cl}(0,4) ; \mathrm{Mn}(0,3), \mathrm{Fe}$ $(0,06), \mathrm{B}(0,05)$ e $\mathrm{Zn}(0,04)$; N; e $\mathrm{K}_{2} \mathrm{O}$ nas concentrações de 10,0 ; 8,0; e 23,2 $\mathrm{g} \mathrm{L}^{-1}$, respectivamente, aos 49 e 64 dias após o plantio.

As unidades experimentais foram representadas pelo sistema solo-cana. Utilizou-se o delineamento inteiramente casualizado, em esquema de parcelas subdivididas; nas parcelas, avaliaram-se os efeitos dos herbicidas e, nas subparcelas, o efeito do tempo após a aplicação dos herbicidas, com quatro repetições.

Quando as plantas de cana-de-açúcar se encontravam com três a quatro folhas expandidas, as unidades experimentais foram aspergidas com solução aquosa dos herbicidas 2,4-D, ametryn, trifloxysulfuron-sodium e ametryn + trifloxysulfuron-sodium, em concentrações equivalentes às doses de 1,$30 ; 1,00 ; 0,0225$; $1,463+0,0375 \mathrm{~kg} \mathrm{ha}^{-1}$, respectivamente. $\mathrm{Na}$ aspersão das soluções herbicidas foi utilizado equipamento de precisão, com pressão constante mantida por $\mathrm{CO}_{2}$ equipado com pontas TT 11002, calibrado previamente para aplicação de $150 \mathrm{~L} \mathrm{ha}^{-1}$ de calda, tendo a pressão

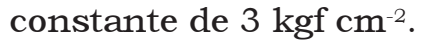

Aos 15, 30, 45 e 60 dias após a aplicação (DAA) foram avaliados: a altura das plantas, o número de folhas, o número de perfilhos, a massa seca da parte aérea e a concentração dos nutrientes nos tecidos foliares.

Para avaliação do estado nutricional das plantas de cana-de-açúcar, foram coletadas amostras das folhas +3 (terceira folha a partir do ápice das plantas), sendo excluída a nervura principal destas, de acordo com metodologia proposta por Malavolta (1997). Após secagem das amostras a $65^{\circ} \mathrm{C}$ até atingirem peso constante, procedeu-se à moagem destas em moinho de lâminas do tipo Willey, equipado com peneira fina (40 mesh), visando maior homogeneização do material. Amostras desse material vegetal moído foram submetidas à digestão nitro-perclórica. Em seguida, foram determinadas as concentrações de fósforo $(\mathrm{P})$, pelo mé-

Tabela 1 - Características físico-químicas do solo Latossolo Vermelho-Amarelo utilizado no experimento, após correção e adubação. Viçosa-MG, 2007

\begin{tabular}{|c|c|c|c|c|c|c|c|c|c|c|}
\hline \multicolumn{11}{|c|}{ Análise granulométrica $\left(\mathrm{dag} \mathrm{kg}^{-1}\right)$} \\
\hline \multicolumn{2}{|l|}{ Argila } & \multicolumn{2}{|l|}{ Silte } & \multicolumn{2}{|l|}{ Areia fina } & \multicolumn{2}{|c|}{ Areia grossa } & \multicolumn{3}{|c|}{ Classe textural } \\
\hline 36 & & 5 & \multicolumn{3}{|c|}{10} & \multicolumn{2}{|c|}{49} & \multicolumn{3}{|c|}{ Argilo-Arenosa } \\
\hline \multicolumn{11}{|c|}{ Análise química } \\
\hline $\mathrm{pH}$ & $\mathrm{P}$ & $\mathrm{K}^{+}$ & $\mathrm{H}+\mathrm{Al}$ & $\mathrm{Al}^{3+}$ & $\mathrm{Ca}^{2+}$ & $\mathrm{Mg}^{2+}$ & $\mathrm{T}$ & $\mathrm{V}$ & & $\mathrm{MO}$ \\
\hline $\mathrm{H}_{2} \mathrm{O}$ & \multicolumn{2}{|c|}{----- $\mathrm{mg} \mathrm{dm}^{-3}$----- } & \multicolumn{5}{|c|}{ - } & \multicolumn{2}{|c|}{------ \% ------ } & --- dag $\mathrm{kg}^{-1}---$ \\
\hline 5,6 & 29,5 & 116,0 & 5,28 & 0,0 & 6,20 & 0,80 & 12,58 & 58,0 & 0 & 2,18 \\
\hline
\end{tabular}


todo da vitamina $\mathrm{C}$ modificado (Braga \& De Fellipo, 1974); de potássio (K), por fotometria de chama (Sarruge \& Haag, 1974); de enxofre (S), por turbidimetria do sulfato (Jackson, 1958); e de cálcio $(\mathrm{Ca})$, magnésio $(\mathrm{Mg})$, ferro $(\mathrm{Fe})$, zinco $(\mathrm{Zn})$, manganês $(\mathrm{Mn})$ e cobre $(\mathrm{Cu})$, por espectrofotometria de absorção atômica (AOAC, 1975). A digestão sulfúrica do material vegetal foi realizada, para determinação da concentração de nitrogênio total (N) pelo método Kjeldahl.

Para interpretação dos dados, foi empregada a análise de variância $(\mathrm{P} \leq 0,05)$; quando as fontes de variação foram significativas, aplicou-se o teste de Tukey a 5\% de probabilidade para comparações das médias dos fatores qualitativos. Foi usada a análise de regressão, a $5 \%$ de probabilidade, para os fatores quantitativos, com a escolha dos modelos baseada na significância dos coeficientes de regressão, utilizando-se o teste "t", no coeficiente de determinação e no fenômeno biológico. Para comparação dos modelos, utilizou-se o método de identidade de modelos proposto por Regazzi (1993).

\section{RESULTADOS E DISCUSSÃO}

As concentrações de macro e micronutrientes observadas nas folhas encontraram-se dentro dos limites da faixa adequada de nutrientes estabelecidos por Malavolta (1997) para cultura de cana-de-açúcar, exceto as concentrações de $\mathrm{K}$ e Mn, ambas superiores aos respectivos limites de máximo da faixa.

A concentração de $\mathrm{N}$ não variou devido à aplicação dos herbicidas, quando comparada à testemunha sem aplicação de herbicida (Tabela 2). Victória Filho \& De Camargo (1980) realizaram um trabalho para verificar possíveis efeitos de herbicidas isolados e em mistura sob a dinâmica de nutrientes na cultura de cana-de-açúcar. Esses autores não constataram alteração na concentração de $\mathrm{N}$ nas folhas de cana-de-açúcar após aplicação de herbicidas.

Os herbicidas, exceto o 2,4-D, não influenciaram a concentração de $\mathrm{K}$ aos 15 e 30 DAA $(\mathrm{P}<0,05)$, quando comparados à testemunha sem herbicida. O 2,4-D favoreceu o aumento de 35 e 41,8\% na concentração de $K$ aos 45 e 60 DAA, respectivamente, em relação à testemunha sem herbicida (Tabela 2).
Quanto aos efeitos dos herbicidas nas concentrações de Ca em plantas de cana-de-açúcar, observaram-se diferenças entre os tratamentos aos 30 DAA $(\mathrm{P}<0,05)$ (Tabela 2). Aos 30 DAA, as concentrações de $\mathrm{Ca}(4,89$ e $5,51 \mathrm{~g} \mathrm{~kg}^{-1}$ ) foram superiores em plantas tratadas com trifloxysulfuron-sodium e 2,4-D, respectivamente.

Ao contrário do observado para o $\mathrm{K} \mathrm{e} \mathrm{Ca}$, verificou-se que o 2,4-D provocou redução na concentração de S (Tabela 2). Aos 15 DAA, observou-se redução de $30 \%$ na concentração de $\mathrm{S}$ em plantas tratadas com 2,4-D, ao passo que o ametryn favoreceu o aumento de $48 \%$ na concentração de $\mathrm{S}\left(4,15 \mathrm{~g} \mathrm{~kg}^{-1}\right)$.

No período de $60 \mathrm{DAA}$, verificaram-se variações de 0,93 a $2,08 \mathrm{~g} \mathrm{~kg}^{-1}$ na concentração de $\mathrm{P}$ e de 13,96 a 25,44 $\mathrm{g} \mathrm{kg}^{-1}$ na concentração de $\mathrm{Mg}$. No entanto, essas variações não decorreram da aplicação dos herbicidas $(\mathrm{P}<0,05)$ (Tabela 2). Em trabalhos realizados nas culturas de trigo, milho e amendoim não foram detectadas alterações nas concentrações foliares dos minerais $\mathrm{P} \mathrm{e} \mathrm{Mg}$ em decorrência da aplicação de chlorsulfuron, atrazine e trifluralin, respectivamente (Deuber et al., 1978; Sharma, 2001; Jakelaitis et al., 2005).

Em relação à testemunha, aos 15 DAA, os herbicidas provocaram redução nas concentrações de $\mathrm{Fe}$ nos tecidos foliares, na seguinte ordem: 2,4-D $\geq$ trifloxysulfuron-sodium $\geq$ ametryn $>$ ametryn+trifloxysulfuron-sodium $>$ testemunha (Tabela 3). Em folhas de plantas tratadas com ametryn verificou-se redução de 40 e de $8 \%$ na concentração de $\mathrm{Fe}$ em relação à testemunha aos 15 e 45 DAA, respectivamente.

No que se refere aos efeitos dos tratamentos nas concentrações de $\mathrm{Zn}$, não se observaram diferenças $(\mathrm{P}<0,05)$ em relação à testemunha (Tabela 3). Com exceção dos 60 DAA, as concentrações de Mn não foram influenciadas pelo tratamento das plantas com herbicidas. O trifloxysulfuron-sodium proporcionou maiores acúmulos de $\mathrm{Mn}$, sendo observado acréscimo de $42 \%$ na concentração deste, em relação à testemunha.

Nos tecidos foliares de plantas tratadas com trifloxysulfuron-sodium aos 30 DAA houve redução de $57 \%$ na concentração de $\mathrm{Cu}$, enquanto com o 2,4-D constatou-se aumento de 
Tabela 2 - Concentrações de macronutrientes foliares de cana-de-açúcar sem aplicação de herbicida e com aplicação de ametryn + trifloxysulfuron-sodium, ametryn, trifloxysulfuron-sodium e 2,4-D, aos 15, 30, 45 e 60 dias após aplicação dos herbicidas (DAA). Viçosa-MG, 2007

\begin{tabular}{|c|c|c|c|c|c|c|}
\hline \multirow{2}{*}{ Tratamento } & \multicolumn{6}{|c|}{ Concentração de macronutrientes $\left(\mathrm{g} \mathrm{kg}^{-1}\right)$} \\
\hline & $\mathrm{N}$ & $\mathrm{K}$ & $\mathrm{Ca}$ & $\mathrm{S}$ & $\mathrm{P}$ & $\mathrm{Mg}$ \\
\hline \multicolumn{7}{|c|}{$15 \mathrm{DAA}$} \\
\hline sem herbicida & $26,23 a b^{1 /}$ & $21,66 \mathrm{a}$ & $3,17 \mathrm{a}$ & $5,97 \mathrm{a}$ & $2,08 \mathrm{a}$ & $21,66 \mathrm{a}$ \\
\hline ametryn + trifloxy. & $27,95 \mathrm{a}$ & $23,54 \mathrm{a}$ & $2,16 \mathrm{a}$ & $5,57 \mathrm{a}$ & $1,94 \mathrm{a}$ & $23,55 \mathrm{a}$ \\
\hline ametryn & $24,33 \mathrm{~b}$ & $22,44 \mathrm{a}$ & $2,74 \mathrm{a}$ & $5,45 \mathrm{ab}$ & $1,76 \mathrm{a}$ & $22,45 \mathrm{a}$ \\
\hline trifloxysulfuron & $25,36 \mathrm{ab}$ & $22,44 \mathrm{a}$ & $3,04 \mathrm{a}$ & $6,49 \mathrm{a}$ & $1,87 \mathrm{a}$ & $22,45 \mathrm{a}$ \\
\hline 2,4-D & $24,33 \mathrm{~b}$ & $21,19 \mathrm{a}$ & $3,21 \mathrm{a}$ & $4,15 \mathrm{~b}$ & $1,86 \mathrm{a}$ & $21,19 \mathrm{a}$ \\
\hline \multicolumn{7}{|c|}{$30 \mathrm{DAA}$} \\
\hline sem herbicida & $22,95 \mathrm{a}$ & $22,29 \mathrm{a}$ & $3,17 \mathrm{c}$ & $3,06 \mathrm{~b}$ & $1,47 \mathrm{a}$ & $22,29 \mathrm{a}$ \\
\hline ametryn + trifloxy. & $23,29 \mathrm{a}$ & $21,50 \mathrm{a}$ & $3,47 \mathrm{bc}$ & $3,03 \mathrm{~b}$ & $1,60 \mathrm{a}$ & $21,51 \mathrm{a}$ \\
\hline ametryn & $23,81 \mathrm{a}$ & $20,87 \mathrm{a}$ & $3,89 \mathrm{bc}$ & $4,54 \mathrm{a}$ & $1,51 \mathrm{a}$ & $20,88 \mathrm{a}$ \\
\hline trifloxysulfuron & $24,15 \mathrm{a}$ & $18,83 \mathrm{a}$ & $4,89 \mathrm{ab}$ & $3,03 \mathrm{~b}$ & $1,40 \mathrm{a}$ & $18,84 \mathrm{a}$ \\
\hline TF2,4-D & $22,86 \mathrm{a}$ & $21,03 \mathrm{a}$ & $5,51 \mathrm{a}$ & $2,95 \mathrm{~b}$ & $1,56 \mathrm{a}$ & $21,04 \mathrm{a}$ \\
\hline \multicolumn{7}{|c|}{45 DAA } \\
\hline sem herbicida & $21,91 \mathrm{a}$ & $18,83 \mathrm{~b}$ & $4,85 \mathrm{ab}$ & $2,75 \mathrm{a}$ & $1,13 \mathrm{a}$ & $18,84 \mathrm{a}$ \\
\hline ametryn + trifloxy. & $21,39 \mathrm{a}$ & $21,03 \mathrm{~b}$ & $4,91 \mathrm{ab}$ & $2,75 \mathrm{a}$ & $1,26 \mathrm{a}$ & $21,04 \mathrm{a}$ \\
\hline ametryn & $21,57 \mathrm{a}$ & $19,77 \mathrm{~b}$ & $6,07 \mathrm{a}$ & $2,90 \mathrm{a}$ & $1,17 \mathrm{a}$ & $19,78 \mathrm{a}$ \\
\hline trifloxysulfuron & $20,19 \mathrm{a}$ & $21,34 \mathrm{~b}$ & $4,23 \mathrm{~b}$ & $2,84 \mathrm{a}$ & $1,09 \mathrm{a}$ & $21,35 \mathrm{a}$ \\
\hline TF2,4-D & $19,84 \mathrm{a}$ & $25,43 \mathrm{a}$ & $5,56 \mathrm{ab}$ & $2,41 \mathrm{a}$ & $1,59 \mathrm{a}$ & $25,44 \mathrm{a}$ \\
\hline \multicolumn{7}{|c|}{60 DAA } \\
\hline sem herbicida & $18,98 \mathrm{a}$ & $14,27 \mathrm{~b}$ & $5,62 \mathrm{ab}$ & $2,56 \mathrm{a}$ & $0,93 \mathrm{a}$ & $14,28 \mathrm{a}$ \\
\hline ametryn + trifloxy. & $19,50 \mathrm{a}$ & $14,59 \mathrm{~b}$ & $6,19 \mathrm{ab}$ & $2,34 \mathrm{a}$ & $1,09 \mathrm{a}$ & $20,88 \mathrm{a}$ \\
\hline ametryn & $20,19 \mathrm{a}$ & $16,32 \mathrm{ab}$ & $6,32 \mathrm{a}$ & $2,97 \mathrm{a}$ & $1,09 \mathrm{a}$ & $16,32 \mathrm{a}$ \\
\hline trifloxysulfuron & $20,36 \mathrm{a}$ & $13,96 \mathrm{~b}$ & $6,69 \mathrm{a}$ & $2,37 \mathrm{a}$ & $1,25 \mathrm{a}$ & $13,96 \mathrm{a}$ \\
\hline TF2,4-D & $19,67 \mathrm{a}$ & $20,24 \mathrm{a}$ & $4,78 \mathrm{~b}$ & $2,38 \mathrm{a}$ & $1,08 \mathrm{a}$ & $20,25 \mathrm{a}$ \\
\hline TRAT*DAA & n.s. & $* *$ & $* *$ & $* *$ & n.s. & n.s. \\
\hline $\mathrm{CV}(\%)$ parcela & 5,39 & 10,32 & 12,72 & 21,26 & 10,89 & 21,80 \\
\hline $\mathrm{CV}(\%)$ subparcela & 8.28 & 10,02 & 17,360 & 17,75 & 11,11 & 19,66 \\
\hline
\end{tabular}

${ }_{1 /}$ Médias seguidas pela mesma letra não diferem entre si pelo teste de Tukey $(\mathrm{P}<0,05)$. n.s. - não-significativo e * e ** " significativo a 0,01 e 0,05 , respectivamente.

$123 \%$ na concentração de $\mathrm{Cu}$ aos 45 DAA, ambas as comparações em relação à testemunha (Tabela 3).

Analisando o efeito do tempo na dinâmica nutricional, observou-se decréscimo nas concentrações dos macronutrientes, exceto na do $\mathrm{Ca}$ (Figura 1). Esse fato foi verificado por Victória Filho \& De Camargo (1980) ao avaliarem os efeitos de herbicidas aplicados em pós-emergência na nutrição mineral da cana-de-açúcar. Segundo Malavolta (1997), as concentra- ções dos macronutrientes em tecidos foliares, de maneira geral, reduzem com a idade da planta, enquanto a concentração de $\mathrm{Ca}$ aumenta na cultura da cana-de-açúcar. Essas reduções podem ser explicadas pelo efeito diluição, isto é, as concentrações dos nutrientes são diluídas com o crescimento da planta (Jarrell \& Beverly, 1981; Mishra \& Kurchania, 2001).

Pelo método de identidade de modelos, não houve diferença significativa $(P<0,05)$ dos coeficientes de regressão $\left(\beta_{1}\right)$ entre modelos 
Tabela 3 - Concentrações de micronutrientes foliares de cana-de-açúcar sem aplicação de herbicida e com aplicação de ametryn + trifloxysulfuron-sodium, ametryn, trifloxysulfuron-sodium e 2,4-D, aos 15, 30, 45 e 60 dias após aplicação dos herbicidas (DAA). Viçosa-MG, 2007

\begin{tabular}{|c|c|c|c|c|}
\hline \multirow{2}{*}{ Tratamento } & \multicolumn{4}{|c|}{ Concentração de micronutrientes $\left(\mathrm{mg} \mathrm{kg}^{-1}\right)$} \\
\hline & $\mathrm{Fe}$ & $\mathrm{Zn}$ & $\mathrm{Mn}$ & $\mathrm{Cu}$ \\
\hline \multicolumn{5}{|c|}{$15 \mathrm{DAA}$} \\
\hline sem herbicida & $163,77 \mathrm{a}^{1 /}$ & $17,36 \mathrm{ab}$ & $227,87 \mathrm{a}$ & $7,18 \mathrm{a}$ \\
\hline ametryn + trifloxy. & $117,65 \mathrm{~b}$ & $19,83 \mathrm{a}$ & $140,00 \mathrm{a}$ & $5,77 \mathrm{a}$ \\
\hline Ametryn & $98,75 \mathrm{c}$ & $16,40 \mathrm{~b}$ & $198,18 \mathrm{a}$ & $6,02 \mathrm{a}$ \\
\hline Trifloxysulfuron & $83,63 \mathrm{~cd}$ & $17,76 \mathrm{ab}$ & $233,00 \mathrm{a}$ & $5,97 \mathrm{a}$ \\
\hline $2,4-\mathrm{D}$ & $77,52 \mathrm{~d}$ & $18,88 \mathrm{ab}$ & $220,00 \mathrm{a}$ & $5,65 \mathrm{a}$ \\
\hline \multicolumn{5}{|c|}{$30 \mathrm{DAA}$} \\
\hline sem herbicida & $73,31 \mathrm{ab}$ & $14,50 \mathrm{a}$ & $271,68 \mathrm{a}$ & $5,31 \mathrm{a}$ \\
\hline ametryn + trifloxy. & $85,85 \mathrm{a}$ & $15,37 \mathrm{a}$ & $250,87 \mathrm{a}$ & $4,63 \mathrm{ab}$ \\
\hline Ametryn & $64,08 \mathrm{~b}$ & $15,18 \mathrm{a}$ & $338,43 \mathrm{a}$ & $3,17 \mathrm{ab}$ \\
\hline Trifloxysulfuron & $62,16 \mathrm{~b}$ & $16,61 \mathrm{a}$ & $342,31 \mathrm{a}$ & $3,05 \mathrm{~b}$ \\
\hline $2,4-\mathrm{D}$ & $71,61 \mathrm{ab}$ & $17,51 \mathrm{a}$ & $359,50 \mathrm{a}$ & $4,42 \mathrm{ab}$ \\
\hline \multicolumn{5}{|c|}{$45 \mathrm{DAA}$} \\
\hline sem herbicida & $68,80 \mathrm{a}$ & $14,55 \mathrm{a}$ & $354,37 \mathrm{ab}$ & $2,33 \mathrm{~b}$ \\
\hline ametryn + trifloxy. & $57,43 \mathrm{ab}$ & $12,53 \mathrm{a}$ & $289,93 \mathrm{~b}$ & $2,61 \mathrm{~b}$ \\
\hline Ametryn & $52,90 \mathrm{~b}$ & $13,28 \mathrm{a}$ & $418,25 \mathrm{a}$ & $2,23 \mathrm{~b}$ \\
\hline Trifloxysulfuron & $55,02 \mathrm{ab}$ & $12,46 \mathrm{a}$ & $301,00 \mathrm{~b}$ & $2,61 \mathrm{~b}$ \\
\hline $2,4-\mathrm{D}$ & $70,11 \mathrm{a}$ & $14,71 \mathrm{a}$ & $296,37 \mathrm{~b}$ & $5,21 \mathrm{a}$ \\
\hline \multicolumn{5}{|c|}{60 DAA } \\
\hline sem herbicida & $61,48 \mathrm{a}$ & $13,56 \mathrm{a}$ & $393,87 \mathrm{bc}$ & $3,48 \mathrm{a}$ \\
\hline ametryn + trifloxy. & $60,81 \mathrm{a}$ & $12,96 \mathrm{a}$ & $374,93 \mathrm{bc}$ & $3,16 \mathrm{a}$ \\
\hline Ametryn & $51,58 \mathrm{a}$ & $13,35 \mathrm{a}$ & $470,87 \mathrm{ab}$ & $2,67 \mathrm{a}$ \\
\hline Trifloxysulfuron & $55,30 \mathrm{a}$ & $14,15 \mathrm{a}$ & $533,12 \mathrm{a}$ & $2,30 \mathrm{a}$ \\
\hline $2,4-\mathrm{D}$ & $50,15 \mathrm{a}$ & $16,01 \mathrm{a}$ & $325,00 \mathrm{c}$ & $3,26 \mathrm{a}$ \\
\hline TRAT $^{*}$ DAA & $* *$ & n.s. & n.s. & $* *$ \\
\hline CV parcela $(\%)$ & 12,21 & 8,18 & 15,45 & 34,45 \\
\hline CV subparcela (\%) & 9,74 & 10,61 & 18,38 & 32,88 \\
\hline
\end{tabular}

${ }^{1 /}$ Médias seguidas pela mesma letra não diferem entre si pelo teste de Tukey $(\mathrm{P}<0,05)$. n.s. - não-significativo, * e ** " significativo a 0,01 e 0,05 , respectivamente

ajustados para a concentração de $\mathrm{P}$ no período de avaliação, sendo estes agrupados em um único modelo comum (Figura 1A, B). De modo similar, as concentrações de $\mathrm{N}$ não foram alteradas ao longo do período de avaliação.

A dinâmica das concentrações dos macronutrientes catiônicos (K, Ca e Mg) apresentou comportamento diferenciado (modelo quadrático) distante em plantas tratadas com 2,4-D no período de 15 a 60 DAA em relação à testemunha (Figura 1D, E, F). A mistura ametryn
+ trifloxysulfuron-sodium proporcionou maiores taxas de acúmulo $\left(\beta_{1}\right)$ de $\mathrm{K}, \mathrm{Ca}$ e $\mathrm{Mg}$ (Figura 1D, E, F).

Para o S, observou-se menor coeficiente de regressão $\left(\beta_{1}\right)$, indicando menor taxa de acúmulo deste em plantas tratadas com 2,4-D (Figura 1C).

Os tratamentos herbicidas não influenciaram as concentrações de Cu dos 15 aos 60 DAA em relação ao tratamento sem aplicação de herbicida, sendo representados por uma única 

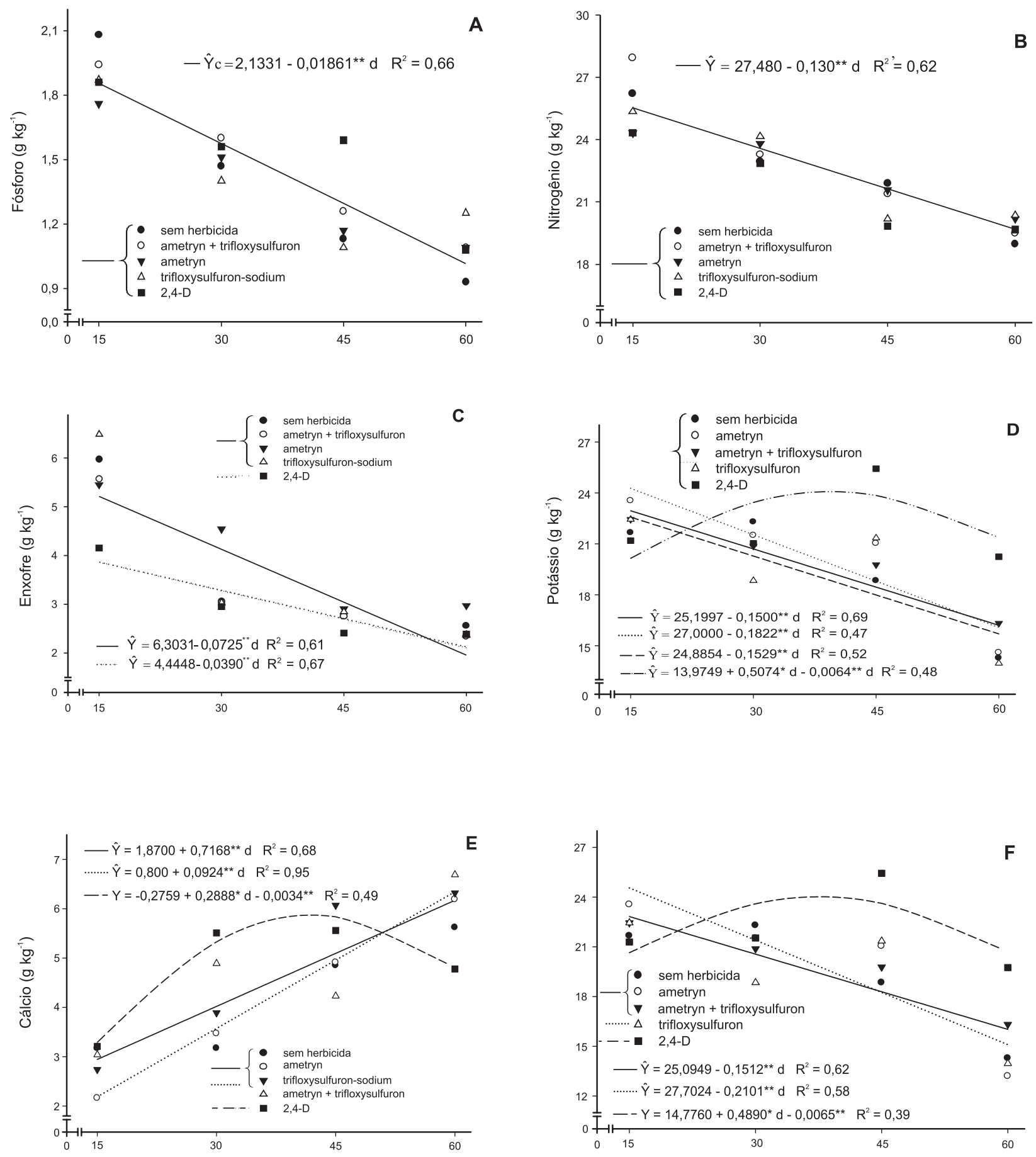

\section{Tempo após aplicação dos herbicidas (d)}

Figura 1 - Dinâmica de fósforo (A), nitrogênio $(\mathbf{B})$, enxofre $(\mathbf{C})$, potássio $(\mathbf{D})$, cálcio $(\mathbf{E})$ e magnésio $(\mathbf{F})$ nos tecidos foliares de canade-açúcar durante 60 dias da aplicação dos herbicidas ametryn+trifloxysulfuron-sodium, ametryn, trifloxysulfuron-sodium e 2,4-D. * e ** significativo a 0,01 e 0,05 , respectivamente. Viçosa-MG, 2007. 

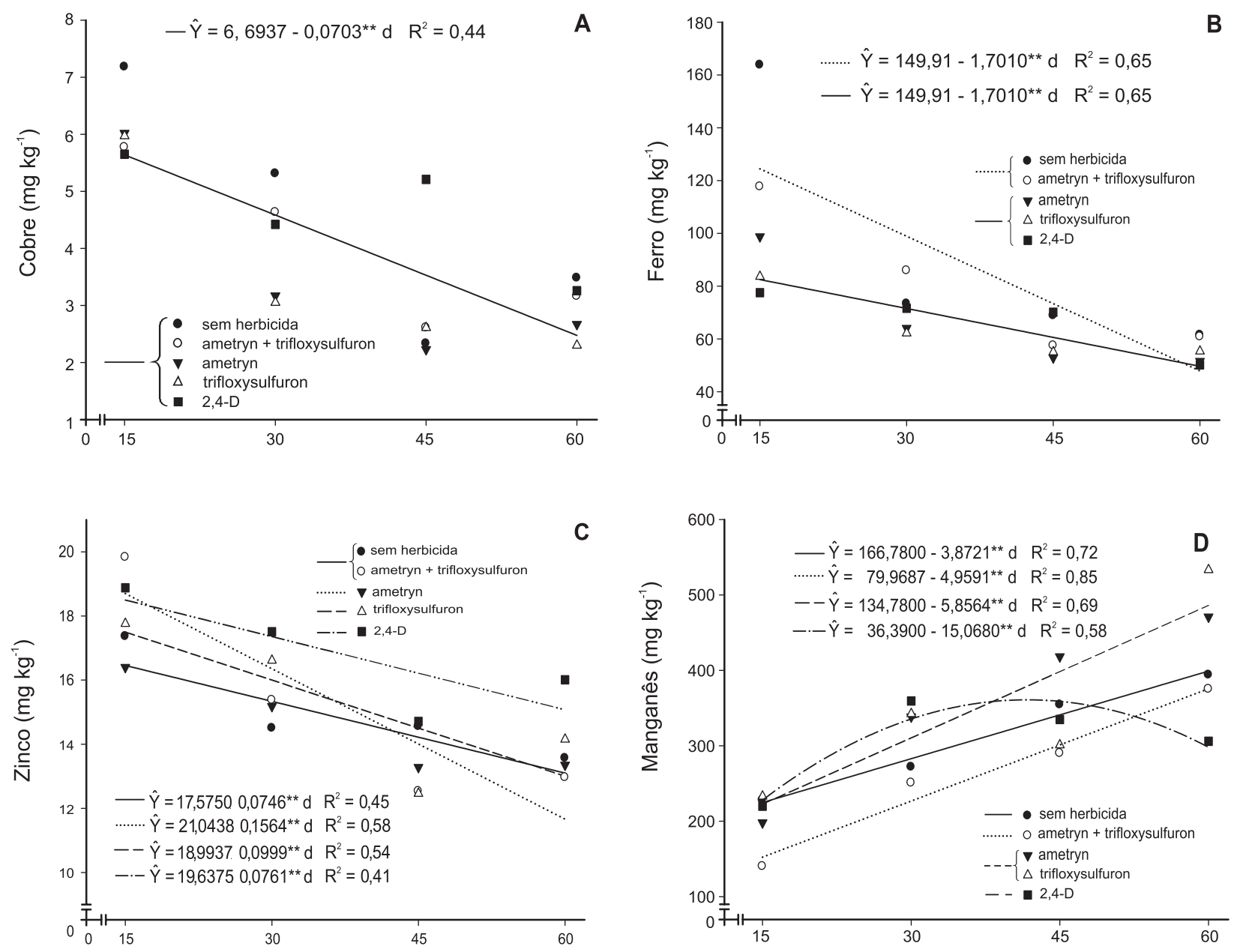

Tempo após aplicação (d)

Figura 2 - Dinâmica de cobre (A), ferro (B), zinco (C) e manganês (D) nos tecidos foliares de cana-de-açúcar durante 60 dias da aplicação dos herbicidas ametryn+trifloxysulfuron-sodium, ametryn, trifloxysulfuron-sodium e 2,4-D. Viçosa-MG, 2007.

equação comum (Figura 2A). No entanto, nesse mesmo período, os modelos ajustados para $\mathrm{Fe}$ foram diferentes em plantas tratadas com ametryn, trifloxysulfuron-sodium e 2,4-D (Figura 2B).

Todos os herbicidas avaliados, com exceção da mistura ametryn + trifloxysulfuron-sodium, interferiram nas concentrações de $\mathrm{Zn}$ no período avaliado (Figura 1C). De modo similar, sem a exceção da mistura ametryn+trifloxysulfuron-sodium, as concentrações de Mn foram alteradas por todos os herbicidas estudados (Figura 1D).

Na Tabela 4, verificam-se incrementos de 18,10 e $12,57 \%$ na altura de plantas tratadas com ametryn aos 15 e 60 DAA, respectivamente. Constatação semelhante foi observada na altura de plantas tratadas com ametryn+trifloxysulfuron-sodium aos 45 DAA $(11,33 \%)$. Sugere-se que a presença do ametryn influencia o aumento do crescimento das plantas de cana-de-açúcar. De acordo com Victória Filho \& De Camargo (1980), há evidências de que herbicidas pertencentes ao grupo das triazinas estimulam o crescimento de plantas de canade-açúcar. Verificou-se redução na altura de plantas tratadas com 2,4-D aos 30 e 45 DAA (Tabela 4). No tratamento trifloxysulfuronsodium, constatou-se aumento da massa seca das plantas aos 60 DAA de $22,10 \%$, em relação àquelas sem aplicação de herbicida (Tabela 4). 
Tabela 4 - Altura de plantas, massa seca da parte aérea, número de folhas e número de perfilhos de plantas de cana-de-açúcar sem aplicação de herbicida e com aplicação de ametryn + trifloxysulfuron-sodium, ametryn, trifloxysulfuron-sodium e 2,4-D, aos 15, 30, 45 e 60 dias após aplicação dos herbicidas (DAA). Viçosa-MG, 2007

\begin{tabular}{|c|c|c|c|c|}
\hline \multirow{2}{*}{ Tratamento } & \multicolumn{4}{|c|}{ Dia após aplicação dos herbicidas } \\
\hline & 15 & 30 & 45 & 60 \\
\hline & \multicolumn{4}{|c|}{ Altura de plantas - CV parcela $=7,49 \%$} \\
\hline sem herbicida & $1,16 \mathrm{bc}^{1 /}$ & $1,60 \mathrm{a}$ & $1,65 \mathrm{~b}$ & $1,75 \mathrm{bc}$ \\
\hline ametryn + trifloxysulfuron & $1,10 \mathrm{c}$ & $1,59 \mathrm{a}$ & $1,87 \mathrm{a}$ & $1,82 \mathrm{ab}$ \\
\hline ametryn & $1,37 \mathrm{a}$ & $1,52 \mathrm{a}$ & $1,66 \mathrm{~b}$ & $1,97 \mathrm{a}$ \\
\hline trifloxysulfuron & $1,36 \mathrm{ab}$ & $1,43 \mathrm{ab}$ & $1,63 \mathrm{~b}$ & $1,69 \mathrm{bc}$ \\
\hline \multirow[t]{2}{*}{ 2,4-D } & $1,18 \mathrm{abc}$ & $1,25 \mathrm{~b}$ & $1,36 \mathrm{c}$ & $1,59 \mathrm{c}$ \\
\hline & \multicolumn{4}{|c|}{ Massa seca parte aérea - CV parcela $=14,06 \%$} \\
\hline sem herbicida & $9,69 \mathrm{a}$ & $19,38 \mathrm{a}$ & $24,92 \mathrm{a}$ & $36,42 \mathrm{~b}$ \\
\hline ametryn + trifloxysulfuron & $6,39 \mathrm{a}$ & $16,50 \mathrm{a}$ & $24,35 \mathrm{a}$ & $33,37 \mathrm{~b}$ \\
\hline ametryn & $10,49 \mathrm{a}$ & $17,80 \mathrm{a}$ & $27,77 \mathrm{a}$ & $38,91 \mathrm{ab}$ \\
\hline trifloxysulfuron & $9,07 \mathrm{a}$ & $18,29 \mathrm{a}$ & $26,95 \mathrm{a}$ & $44,47 \mathrm{a}$ \\
\hline \multirow[t]{2}{*}{$2,4-\mathrm{D}$} & $7,41 \mathrm{a}$ & $16,95 \mathrm{a}$ & $27,12 \mathrm{a}$ & $38,73 \mathrm{ab}$ \\
\hline & \multicolumn{4}{|c|}{ Número de folhas - CV parcela $=6,07 \%$} \\
\hline sem herbicida & $7,50 \mathrm{a}$ & $8,25 \mathrm{~b}$ & $10,87 \mathrm{a}$ & $11,75 \mathrm{a}$ \\
\hline ametryn + trifloxysulfuron & $7,50 \mathrm{a}$ & $10,12 \mathrm{a}$ & $11,37 \mathrm{a}$ & $10,50 \mathrm{ab}$ \\
\hline ametryn & $7,37 \mathrm{a}$ & $8,87 \mathrm{ab}$ & $10,50 \mathrm{a}$ & $10,87 \mathrm{ab}$ \\
\hline trifloxysulfuron & $7,87 \mathrm{a}$ & $9,25 \mathrm{ab}$ & $10,62 \mathrm{a}$ & $10,25 \mathrm{~b}$ \\
\hline \multirow[t]{2}{*}{ 2,4-D } & $7,12 \mathrm{a}$ & $9,00 \mathrm{ab}$ & $10,50 \mathrm{a}$ & $10,62 \mathrm{ab}$ \\
\hline & \multicolumn{4}{|c|}{ Número de perfilhos - CV parcela $=32,31 \%$} \\
\hline sem herbicida & $1,62 \mathrm{a}$ & $1,75 \mathrm{a}$ & $1,75 \mathrm{a}$ & $2,87 \mathrm{ab}$ \\
\hline ametryn + trifloxysulfuron & $0,5 \mathrm{a}$ & $1,37 \mathrm{a}$ & $1,37 \mathrm{a}$ & $2,00 \mathrm{~b}$ \\
\hline ametryn & $1,62 \mathrm{a}$ & $1,25 \mathrm{a}$ & $2,25 \mathrm{a}$ & $1,75 \mathrm{~b}$ \\
\hline trifloxysulfuron & $1,75 \mathrm{a}$ & $1,62 \mathrm{a}$ & $2,12 \mathrm{a}$ & $3,50 \mathrm{a}$ \\
\hline 2,4-D & $0,87 \mathrm{a}$ & $1,50 \mathrm{a}$ & $2,12 \mathrm{a}$ & $2,50 \mathrm{ab}$ \\
\hline
\end{tabular}

${ }^{1 /}$ Médias seguidas pela mesma letra não diferem entre si pelo teste de Tukey $(\mathrm{P}<0,05)$.

Essa maior produção de MS pode ser atribuída ao maior número de folhas observado em plantas tratadas com ametryn+trifloxysulfuronsodium aos 30 DAA. Nos demais tratamentos não houve diferença $(\mathrm{P}<0,05)$, em relação à testemunha, quanto à $\mathrm{MS}$ produzida. $\mathrm{O}$ número de perfilhos de plantas não foi influenciado pelos herbicidas, comparado ao da testemunha, no período de avaliação (Tabela 4).

De maneira geral, as concentrações de macronutrientes nas plantas não foram influenciadas pela aplicação de ametryn e trifloxysulfuron-sodium isoladamente ou em mistura e houve pouca influência pela aplicação do $2,4-$
D em relação à testemunha, nas respectivas épocas de avaliação. No entanto, a dinâmica dos nutrientes catiônicos $\mathrm{K}, \mathrm{Ca}$ e $\mathrm{Mg}$, ao longo do tempo da avaliação, foi influenciadas pela aplicação do 2,4-D e também pela mistura ametryn+trifloxysulfuron-sodium. As concentrações de micronutrientes dos tecidos foliares foram pouco influenciadas pelos herbicidas, com exceção do micronutriente Fe aos 15 DAA. $\mathrm{O}$ tratamento 2,4-D apresentou maiores diferenças na dinâmica dos micronutrientes no período de avaliação, exceto na do Fe. Os mecanismos de absorção de macro e micronutrientes ainda são pouco esclarecidos (Buchanan, 2000), e o comportamento dos herbicidas na 
planta, bastante complexos e pouco elucidados, impossibilitando inferências sobre a influência dos herbicidas na absorção diferenciada dos nutrientes pelas plantas.

\section{AGRADECIMENTOS}

Ao Conselho Nacional de Desenvolvimento Científico e Tecnológico (CNPq), pelo apoio financeiro para a realização deste trabalho.

\section{LITERATURA CITADA}

ANVISA - Agência Nacional de Vigilância Sanitária. Disponível em: < http://www.anvisa.gov.br/agrosia/asp/ default.asp>. Acesso em: 01/11/2006

AOAC- Association of official analytical chemists. Official methods of analysis. $12 \mathrm{ed}$. Washigton, D. C., 1975, $1094 \mathrm{p}$

BRAGA, J. M.; DE FELLIPO, B. V. Determinação espectofotométrica de fósforo em extratos de solos e plantas. Revista Ceres, v. 21, n. 113, p. 73-85, 1974.

BUCHANAN, B.; GRUISSEM, W.; JONES, R. L. Biochemistry and biology molecular of plants. ASPP, Rockville, Marylan, USA, 2000. 1408 p.

CHABOUSSOU, F. Plantas doentes pelo uso de agrotóxicos: a teoria da trofobiose. 2 . ed. Porto Alegre: $\mathrm{L}$ \&PM, 1999. 272p.

DURIGAN, J. C.; TIMOSSI, P. C.; CORREIA, N. M. Densidades e manejo químico da tiririca na produtividade de cana-de-açúcar. Planta Daninha, v. 23, n. 3, p. 463-469, 2005.

DURIGAN, J. C.; TIMOSSI, P. C.; CORREIA, N. M. Manejo integrado da tiririca na produtividade de cana-deaçúcar. Planta Daninha, v. 24, n. 1, p. 77-81, 2006.

FERREIRA, E. A et al. Sensibilidade da cana-de-açúcar à mistura trifloxysulfuron-sodium + ametryn. Planta Daninha, v. 23, n. 1, p. 93-99, 2005

FREITAS, S. P. et al. Chemical control of Rottboellia exaltata in sugarcane. Planta Daninha, v. 22, n. 3, p. 461-466, 2004.

HUDETZ, M.; W. FOERY, J. W.; SOARES, J. E. CGA 362622, a new low rate Novartis post-emergent herbicide for cotton and sugarcane. Proc. South. Weed Sci. Soc., v. 53, p. $163-166,2000$.

JACKSON, M. L. Soil chemical analysis. New Jersey, Prentice Hall, Inc., 1958. 498 p
JAKELAITIS, A. et al. Influência de herbicidas e sistemas de semeadura de Brachiaria Brizantha consorciada com milho. Planta Daninha, v. 23, n. 1, p. 59-67, 2005.

JARRELL, W. M.; BEVERLY, R. B. The dilution effect in plant nutrition studies. Adv. Agron., v. 34, p. 197-224, 1981.

MAGALHÃES, P. G. In: BARBIERI, J. 30 anos do Proálcool no centro do debate. J Unicamp. ed. 309, p. 11, 2005.

MALAVOLTA, E.; VITTI, G. C.; OLIVEIRA, S. A. Avaliação do Estado Nutricional das Plantas. 2. ed Potafos, Piracicaba, SP. 1997. 319 p.

MISHRA, J. S; KURCHANIA, S. P Nutrient content in mustard and associated weeds as influenced by nitrogen levels, planting geometry and weed control methods. Indian J. Plant Physiol., v. 6, n. 4, p. 386-389, 2001.

PMGCA - Programa de melhoramento genético de canade-açúcar. Disponível em: <http://www.ufv.br/dft/cana/ cana.htm $>$ Acesso em: 10/11/2005.

PROCÓPIO, S. O. et al. Manejo de plantas daninhas na cultura da cana de açúcar. Viçosa, MG: Universidade Federal de Viçosa, p. 150, 2003

RANA, S. S; ANGIRAS, N. N.; SHARMA, G. D. Effect of herbicides and interculture on nutrient uptake by puddle seeded rice and associated weeds. Indian J. Weed Sci., v. 32, n. 1, p. $70-73,2000$.

REGAZZI, A. J. Teste para verificar a igualdade de modelos de regressão e a igualdade de alguns parâmetros num modelo polinomial ortogonal. Revista Ceres, v. 40, n. 228, p. 176195, 1993.

RODRIGUES, B. N.; ALMEIDA, F. R. Guia de herbicidas. 5. ed., Londrina: Edição dos Autores, 2005. 591 p.

SHARMA, R.; PAHUJA, S. S. Effect of weed control measures on nutrient uptake by crop and weeds in wheat (Triticum aestivum L.) Indian J. Weed Sci., v. 33, n. 3, p. 174-176, 2001

SILVA, A. A. et al. Métodos de controle de plantas daninhas In: SILVA, A. A.; SILVA, J. F. (Eds.). Tópicos em manejo de plantas daninhas. Viçosa: Ed. UFV, 2007. 367 p.

VICTÓRIA FILHO, R.; DE CAMARGO, P. N. Efeitos de herbicidas nos concentrações de macronutrientes e nas características tecnológicas da cana-de-açúcar (Saccharum spp.). I-Misturas de herbicidas em pós-emergência. Planta Daninha, v. 3, n. 2, p. 96-107, 1980. 